\title{
Long-term accuracy of MDF milling process-development of adaptive control system corresponding to progression of tool wear
}

\author{
K. Laszewicz · J. Górski $・$ J. Wilkowski
}

Received: 12 June 2012/ Published online: 22 February 2013

(C) The Author(s) 2013. This article is published with open access at Springerlink.com

\begin{abstract}
The study describes a new adaptive control system corresponding to progression of tool wear. The idea was based on an original machine vision system used for measuring the dimensions of workpieces. It turned out that the new adaptive control system might be quite effective. A significant improvement (from IT16 to IT12) of long-term MDF milling process accuracy was observed. Moreover, it was found that direct measurement of cutting errors based on workpieces vision inspection was generally more useful than tool wear monitoring. The real cutting errors observed for MDF side milling were neither equal nor even strictly proportional to the errors which would be expected, or explainable, only on the basis of the real decrease in the diameter of end mill (the decrease being the obvious result of tool wear progression).
\end{abstract}

Langzeitgenauigkeit bei der MDF-Bearbeitung - Entwicklung eines adaptiven Systems zur Kontrolle des Werkzeugverschleißes

\section{Introduction}

One of the most important problems in machining is longterm maintenance of dimensional accuracy of the process in spite of unavoidable tool wear progression. For this reason Ohuchi and Murase $(2005,2006)$ developed an adaptive control grooving system corresponding to the

K. Laszewicz · J. Górski · J. Wilkowski ( $₫)$

Faculty of Wood Technology, Warsaw University of Life

Sciences-SGGW, 159 Nowoursynowska St.,

02-776 Warsaw, Poland

e-mail: jacek_wilkowski@sggw.pl progression of tool wear. This system was based on laser measuring of the cutting edge profile.

The paper presents a new idea of an adaptive control system corresponding to the progression of tool wear. The focus of the study was put on the dimensional accuracy of MDF side milling.

\section{Materials and methods}

A standard CNC router and carbide tipped end mill were used in the test. The final goal of MDF machining was the dimension "A" (10 mm nominal) which was formed as the result of two processes of side milling (Fig. 1). The maximum value of flank wear (VBmax) and decrease in diameter of end mill were adopted as tool wear indicators and monitored by means of a microscope (Mitutoyo TM$500)$.

The experiment was conducted until the VBmax indicator reached $0.4 \mathrm{~mm}$. It should be emphasised that the experiment was comprised of two parallel productive processes. Both processes were conducted alternately with the same tool. The first process, referred to as standard process, consisted of manufacturing the objects without any external intervention in CNC programme. The second process, referred to as revised process, was conducted with the use of an adaptive control system corresponding to the progression of tool wear. The basis of the adaptive control system was an original machine vision system which was used for measuring of workpieces ' dimensions (strictly speaking: for the dimension " $\mathrm{A}$ " measuring). The results of the automatic measurement were used for periodic ("off-line") revision of CNC program. The general scheme of the tested system is shown in Fig. 2. The original software for the analysis of the workpieces digital images (2D 


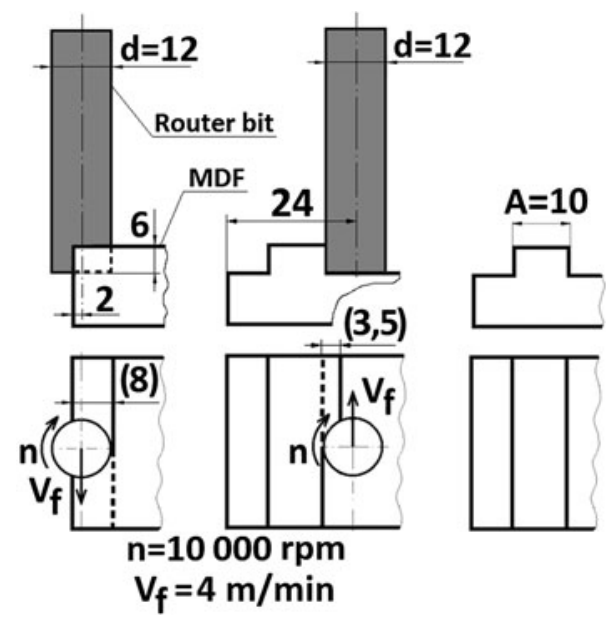

Fig. 1 Scheme of MDF machining ( $A$-workpiece dimension, which was the final goal of machining; $d$-cutting diameter; $n$-spindle speed; $V_{f}$-feed speed)

Abb. 1 Bearbeitungsschema ( $A$ - Sollabmessung des Werkstücks; $d$ Spindeldurchmesser; $n$-Spindeldrehzahl; $V_{f}$-Vorschubgeschwindigkeit)

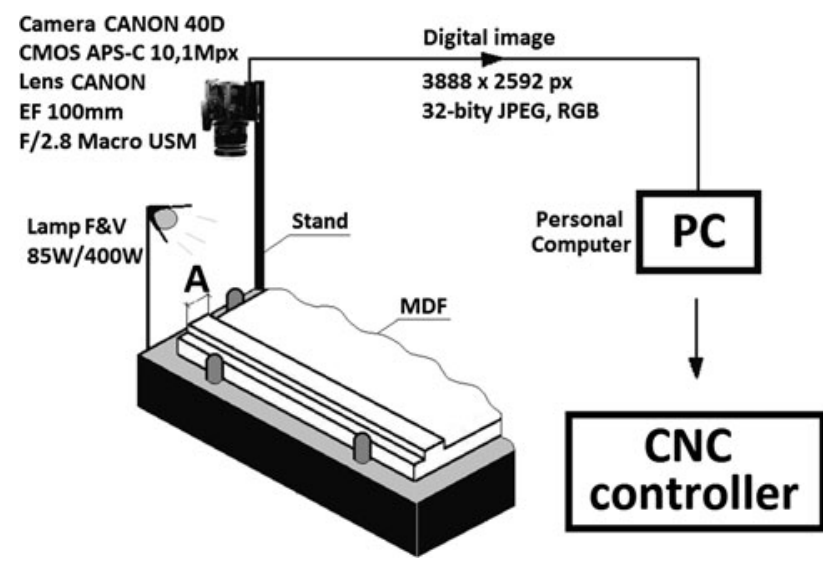

Fig. 2 Scheme of adaptive control system corresponding to progression of tool wear

Abb. 2 Schematische Darstellung des adaptiven Systems zur Kontrolle des Werkzeugverschleißes

visible light) to extract data for controlling a milling process was developed by means of NI LabVIEW. Apart from the visual measuring, all the manufactured workpieces were measured with a regular micrometer to determine the real cutting errors in a standard way.

\section{Results and discussion}

The real cutting errors observed for dimension A during both processes (standard and revised) are illustrated in Fig. 3.

Apart from the real cutting errors, the hypothetical errors are marked with the broken line. The hypothetical errors are the ones forecasted on the basis of the real tool diameter that is on the basis of the results of microscope
- : standard process

- revised process

- hypothetical errors of standard process

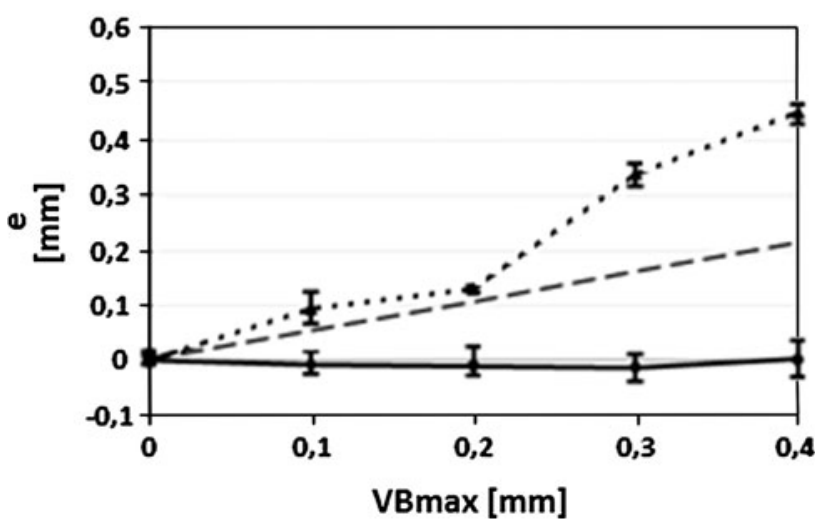

Fig. 3 Relation between tool wear and dimensional accuracy of cutting (VBmax - maximum value of flank wear, $e$-cutting error calculated as the difference between nominal and real dimension of workpiece)

Abb. 3 Zusammenhang zwischen Werkzeugverschleiß und Bearbeitungsgenauigkeit (VBmax - maximaler Verschleiß, $e-$ Bearbeitungsfehler berechnet aus der Differenz zwischen nominaler und tatsächlicher Abmessung des Werkstücks)

measuring of the milling cutter diameter recession. As it can be easily observed, the real cutting errors, detected during the revised process, were not rising along with the tool wear progress. Such interdependence was observed in case of the standard process. Moreover, it turned out that the real cutting errors observed for MDF side milling were neither equal nor even strictly proportional to the errors which would be expected, or explainable, only on the basis of the real decrease in the diameter of end mill (the decrease being the obvious result of tool wear progression). Therefore the direct measurement of cutting errors, based on workpieces vision inspection, was generally more useful than the tool wear monitoring. It is worth noting that adaptive control system based on laser measuring of the cutting edge profile (Ohuchi and Murase 2006) was developed and tested only for grooving.

The standard statistical results analysis was carried out with the use of ISO 21747 2006. On this basis long-term tolerances were calculated and compared with ISO 286-1,2 2010 requirements. It was shown that the tested idea of adaptive control system allows to meet the IT12 requirements (revised process). In case of the standard process, the accuracy level was much worse (IT16).

\section{Conclusion}

In this paper the presented idea of an adaptive control system corresponding to progression of tool wear turned 
out to be quite effective. The significant improvement of dimensional accuracy was observed. Moreover, it turned out that direct measurement of cutting errors, based on workpieces vision inspection, was generally more useful than the tool wear monitoring.

Open Access This article is distributed under the terms of the Creative Commons Attribution License which permits any use, distribution, and reproduction in any medium, provided the original author(s) and the source are credited.

\section{References}

ISO 21747 (2006) Statistical methods-Process performance and capability statistics for measured quality characteristics
ISO 286-1,2 (2010) Geometrical product specifications (GPS)—ISO code system for tolerances on linear sizes

Ohuchi T, Murase Y (2005) Milling of wood and wood-based materials with a computerized numerically controlled router IV: development of automatic measurement system for cutting edge profile of throw-away type straight bit. J Wood Sci 51:278-281

Ohuchi T, Murase Y (2006) Milling of wood and wood-based materials with a computerized numerically controlled router $\mathrm{V}$ : development of adaptive control grooving system corresponding to progression of tool wear. J Wood Sci 52:395-400 